\title{
Effects of glucocorticoids in ventilated piglets with severe pneumonia
}

\author{
O. Sibila*,\#, C.M. Luna", C. Agustí*,\#, S. Baquero`, S. Gando ", J.R. Patrón \\ J.G. Morato ${ }^{+}$, R. Absi ${ }^{\S}$, N. Bassi ${ }^{\dagger}$ and A. Torres*,\#
}

ABSTRACT: There is clinical evidence suggesting that glucocorticoids may be useful in severe pneumonia, but the pathogenic mechanisms explaining these beneficial effects are unknown.

The aim of the present study was to determine the effects of adding glucocorticoids to antibiotic treatment in an experimental model of severe pneumonia.

In total, 15 Lagerwhite-Landrace piglets were ventilated for $96 \mathrm{~h}$. After intubation, a $75 \mathrm{~mL}$ solution containing Pseudomonas aeruginosa $\left(10^{6} \mathrm{cfu} \cdot \mathrm{mL}^{-1}\right)$ was bronchoscopically inoculated. The animals were randomised into three groups $12 \mathrm{~h}$ after inoculation: 1) untreated; 2) treated with ciprofloxacin; and 3) treated with ciprofloxacin plus methylprednisolone. Physiological and laboratory parameters were monitored throughout the study. Pro-inflammatory cytokines were measured in serum and bronchoalveolar lavage (BAL). Histopathology of the lungs and cultures from blood, BAL and lungs were performed.

At the end of the study, piglets receiving the antibiotic plus glucocorticoids showed: 1) a decrease in the concentration of interleukin-6 in BAL; and 2) a decrease in the global bacterial burden both in BAL and lung tissue.

In conclusion, in this experimental model of pneumonia, the association of glucocorticoids with antibiotics attenuates local inflammatory response and decreases bacterial burden in the lung.

KEYWORDS: Glucocorticoids, inflammatory response, piglets, Pseudomonas aeruginosa, severe pneumonia, ventilator-associated pneumonia

$\mathrm{T}$ he mortality rate in severe community- or hospital-acquired pneumonia requiring mechanical ventilation is very high $[1,2]$. Moreover, despite advances in antimicrobial therapy and supportive measures, this rate has not changed over the last few years [3-5], suggesting that other factors are also responsible for the poor outcome. The role of the host inflammatory response in the evolution of bacterial infections has been shown to be crucial, with the release of cytokines and other inflammatory mediators from immune cells being important for the elimination of invading pathogens. However, an excessive release of these mediators can be harmful to the host and in particular to the lung. Different clinical studies have shown associations between the concentration of relevant inflammatory cytokines in bronchoalveolar lavage (BAL) fluid or serum and pneumonia severity $[6,7]$. It has also been shown that persistent elevation of these cytokines has prognostic implications in severe pneumonia and acute respiratory distress syndrome (ARDS) [7-10].

Glucocorticoids (GCs) decrease the local and systemic inflammatory response. These compounds inhibit the recruitment of leukocytes and monocyte-macrophages into affected areas [11], and affect the expression and activity of a great variety of cytokines relevant to the inflammatory response in pneumonia, including interleukin (IL)$1 \beta$, IL-6 and tumour necrosis factor (TNF)- $\alpha$ [12].

Different controversial results have generated an intense debate regarding the benefits of prolonged GC treatment at low-to-moderate doses in patients with catecholamine-dependent septic shock [13,14] and acute lung injury and ARDS [15-17]. Also, GC administration is indicated in severe Pneumcystis jiroveci pneumonia [18]. In addition, CONFALONIERI et al. [19] reported that in patients suffering from severe communityacquired pneumonia (CAP), continuous endovenous infusion of low-dose hydrocortisone improved survival.

Multiple factors may influence the inflammatory response and the outcome of patients with severe pneumonia, particularly those receiving mechanical ventilation. In this sense, the availability of an animal model of severe pneumonia may greatly enhance both knowledge of the mechanisms
AFFILIATIONS

*Pneumology Service, Thorax Clinic Institute, Hospital Clinic, Institut dlnvestigacions Biomèdiques Augus Pi i Sunyer (IDIBAPS), University of Barcelona, and

${ }^{*}$ Ciber Enfermedacles Respiratorias (CIBERes), Barcelona, Spain.

"Pneumology Division, +Experimental Surgery, ${ }^{\S}$ Biomedical Division, and ${ }^{f}$ Pathology Division, Hospital de Clínicas "Jose de San Martin", University of Buenos Aires, Buenos Aires City, Argentina.

CORRESPONDENCE

A. Torres, Servei de Pneumologia, Hospital Clínic, Villarroel 170.08036 Barcelona, Spain. Fax: 34 932275549

E-mail: atorres@ub.edu

Received:

January 192008

Accepted after revision:

May 092008

\section{SUPPORT STATEMENT}

This work was supported by the Spanish Society of Pulmonology and Thoracic Surgery (SEPAR), Mutual Mèdica de Catalunya i Balears (MMCB), Fondo de Investigación Sanitaria (FIS) PI 050136, FIS PI 030113, CIBERes and IDIBAPS.

STATEMENT OF INTEREST

None declared. 
involving inflammatory response and the understanding of the efficacy of pharmacological interventions. Moreover, the effects of GCs on the modulation of inflammatory response in pneumonia and their potential microbiological and histopathological consequences may be better elucidated.

MARQUETTE et al. [20] have standardised an animal model of pneumonia in ventilated piglets. This model closely resembles human pneumonia and has proven to be very useful for evaluating different aspects related to the diagnosis and treatment of severe pneumonia [21-27]. Using this animal model, severe pneumonia was reproduced and the associated inflammatory response was studied after inoculation with high concentrations of Pseudomonas aeruginosa [28], the most lethal causative microorganism, both in CAP and ventilator-associated pneumonia $[2,8,29]$.

The current authors hypothesised that the concomitant administration of GCs with antibiotics might decrease the local and systemic inflammatory response with subsequent beneficial effects on the severity of pneumonia.

The aim of the present study was, therefore, to investigate the potential benefits of GC in addition to antibiotic treatment in an experimental model of pneumonia induced by $P$. aeruginosa in ventilated piglets. Of particular interest was identifying the effects of GCs on inflammatory response (both local-lung and systemic-serum) and on clinical, microbiological and histopathological variables.

\section{METHODS}

\section{Animal preparation}

In total, 19 healthy domestic-bred Largewhite-Landrace piglets, aged 3 months and weighing $20 \pm 2 \mathrm{~kg}$ were anaesthesised and orotracheally intubated. The femoral artery was cannulated for pressure monitoring and blood sampling, a catheter was inserted in the femoral vein for continuous infusion and a suprapubic urinary catheter was placed in the bladder through surgical midline minipelvitomy. The piglets were then placed in a prone position and were mechanically ventilated for 4 days. Ventilator parameters consisted of tidal volume $(V \mathrm{~T})$ of $10 \mathrm{~mL} \cdot \mathrm{kg}^{-1}$, a respiratory frequency of $15 \mathrm{breaths} \cdot \mathrm{min}^{-1}$, an inspiratory time of $33 \%$, with an inspiratory oxygen fraction $\left(\mathrm{FI}, \mathrm{O}_{2}\right)$ of $100 \%$ and a positive end-expiratory pressure of 0 , as described previously [28].

\section{Bronchial inoculation}

Animals were inoculated with $75 \mathrm{~mL}$ of a suspension of $10^{6}$ colony forming units $(\mathrm{cfu}) \cdot \mathrm{mL}^{-1}$ of pathogenic $P$. aeruginosa
ATCC 27853, susceptible to ciprofloxacin (minimal inhibitory concentration $0.5 \mu \mathrm{g} \cdot \mathrm{mL}^{-1}$ ). Infusion of $15 \mathrm{~mL}$ was evenly distributed in every lobe of each lung through the bronchoscope channel.

\section{Study design}

To determine the effect of GCs on different clinical, microbiological and histopathological variables, and on inflammatory parameters, animals were randomised into three groups $12 \mathrm{~h}$ after the inoculation of $P$. aeruginosa. The first group consisted of five animals receiving serum alone (control group). The second group included five animals receiving i.v. ciprofloxacin (200 mg) every $12 \mathrm{~h}$ (CIP group) and the third group included five animals receiving i.v. ciprofloxacin (200 mg) every $12 \mathrm{~h}$ plus GCs (i.v. methylprednisolone $0.5 \mathrm{mg} \cdot \mathrm{kg}^{-1}$ every $12 \mathrm{~h}$; CIP+GC group). In keeping with the present research protocol, piglets of each group were under mechanical ventilation for $84 \mathrm{~h}$ [28]. Piglets that died in the first $12 \mathrm{~h}$ were excluded from the study.

\section{End-points}

Clinical, haemodynamic and biochemical data, respiratory mechanics, inflammatory mediators in serum and BAL fluid (TNF- $\alpha$, IL-1 $\beta$, IL-6, IL-8 and C-reactive protein (CRP)), type and degree of histopathological pulmonary lesions and quantitative bacteriological studies were evaluated at different time-points in the three groups of animals studied. A summary of the study design is displayed in figure 1.

Specific drug assignment was known by the investigators, but biochemical, biological, microbiological and histopathological studies were performed blindly.

\section{Samplings and procedures}

Heart rate, blood pressure, body temperature, mechanical ventilation parameters (airway pressures, static pulmonary compliance [30] and $\mathrm{FI}_{1} \mathrm{O}_{2}$, arterial blood gases (IL-1306; Instrumentation Laboraties, Milan, Italy), serum electrolytes (sodium, potassium) and lactate concentrations were monitored at $0,2,6,12,24,36,48,60,72,84$ and $96 \mathrm{~h}$. Blood biochemistry (glucose, creatinine, urea, bilirubin, aspartate aminotransferase and alanine aminotransferase) and blood cells count were obtained at $0,24,48,72$ and $96 \mathrm{~h}$.

For BAL, five $20-\mathrm{mL}$ aliquots of sterile saline solution $(0.9 \%$ $\mathrm{NaCl}$ ) were instilled through the bronchoscope channel and subsequently aspirated by hand at $0 \mathrm{~h}$ (immediately before $P$. aeruginosa inoculation) in the right middle lobe.

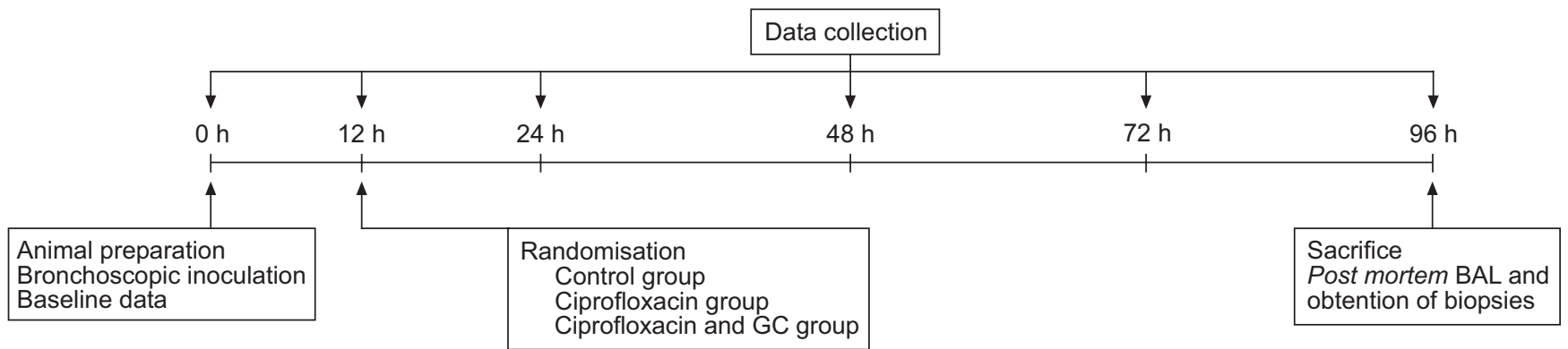

FIGURE 1. Schematic of determinations and different interventions in ventilated piglets. GC: glucocorticoid; BAL: bronchoalveolar lavage. 


\section{Inflammatory parameters}

C-reactive protein

CRP was quantified in serum and BAL fluid using a CRP kit (Biosystems SA, Barcelona, Spain).

Cytokines in blood and BAL fluid

TNF- $\alpha$, IL-1 $\beta$, IL- 6 and IL- 8 levels were measured in serum and BAL supernatant using the ELISA method in specific porcine kits (R\&D Systems Inc., Minneapolis, MN, USA).

BAL cytokine and CRP levels were determined at the time of intubation and at the end of the study. Serum cytokines and CRP were determined at the time of intubation and at $24,48,72$ and $96 \mathrm{~h}$.

\section{Sacrifice and post mortem studies}

Sacrifice was performed on day 4 under general anaesthesia by i.v. potassium chloride infusion.

\section{Collection of lung specimens}

After death, animals remained mechanically ventilated up to the time of specimen collection. Lungs were aseptically exposed through a cervicothoracic midline incision. BAL was performed in both the macroscopically more preserved and more involved lung lobes. BAL specimens were processed for cytokine measurements and quantitative bacterial cultures.
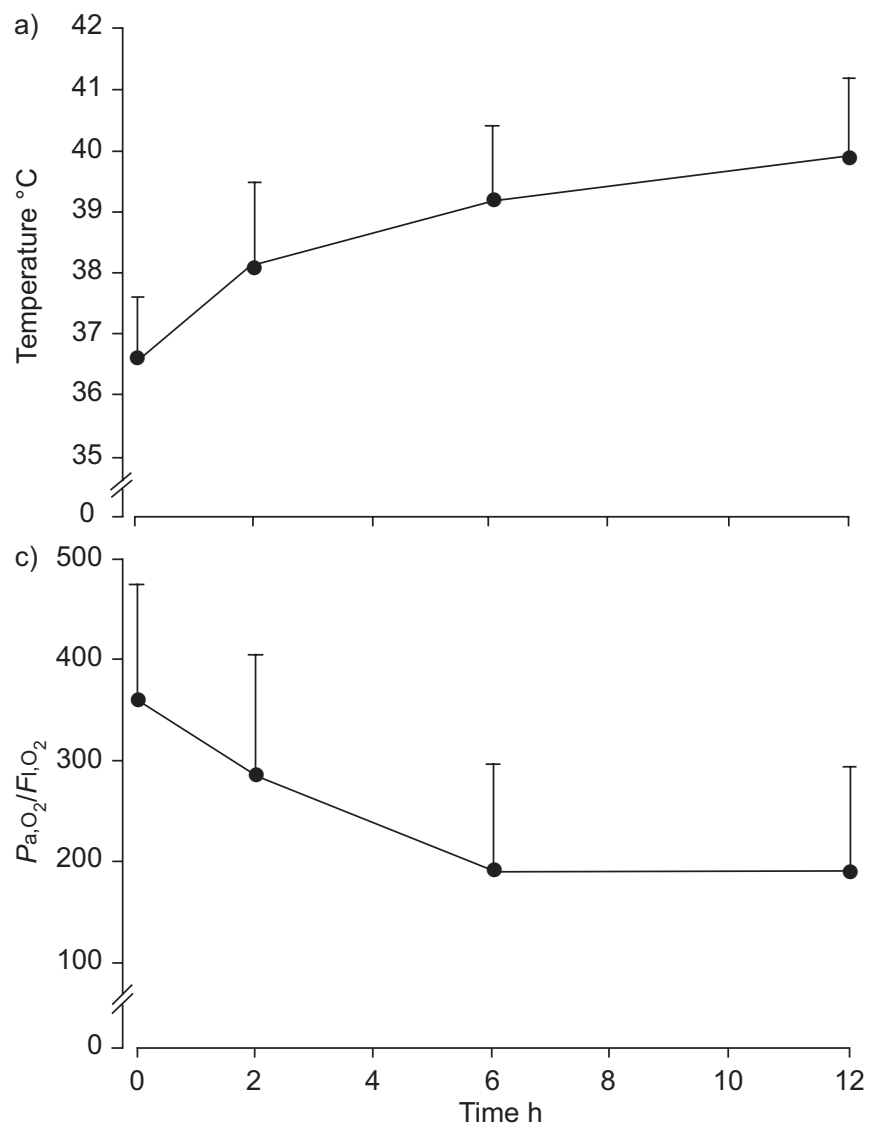

Thereafter, at least one lung tissue specimen $\left(3 \mathrm{~cm}^{3}\right)$ was taken from the aforementioned lobes (the more preserved and involved), while the lungs were kept inflated. Specimens were cut into two parts for bacteriological and pathological studies.

\section{Bacteriological studies}

Blood culture and quantitative BAL and lung tissue cultures were performed immediately at post mortem with animals remaining under mechanical ventilation.

BAL and lung tissue specimens were processed for quantitative bacterial cultures as described elsewhere [31] according to recommended laboratory methods [32].

The global bacterial burden was assessed by calculating the median of the different bacterial count samples taken from the more preserved lobe and the more involved lobe (both in BAL fluid and lung tissue).

\section{Pathological studies}

Lung tissue was processed according to standard methods. Pneumonia lesions were graded according to previously published criteria [33] in the following grades. 0: no pneumonia; 1: purulent mucous plugging; 2: bronchiolitis; 3: pneumonia (consolidation coexisting with significant accumulation of polymorphonuclear leukocytes, fibrinous exudates and cellular debris into the alveolar space); 4: confluent pneumonia
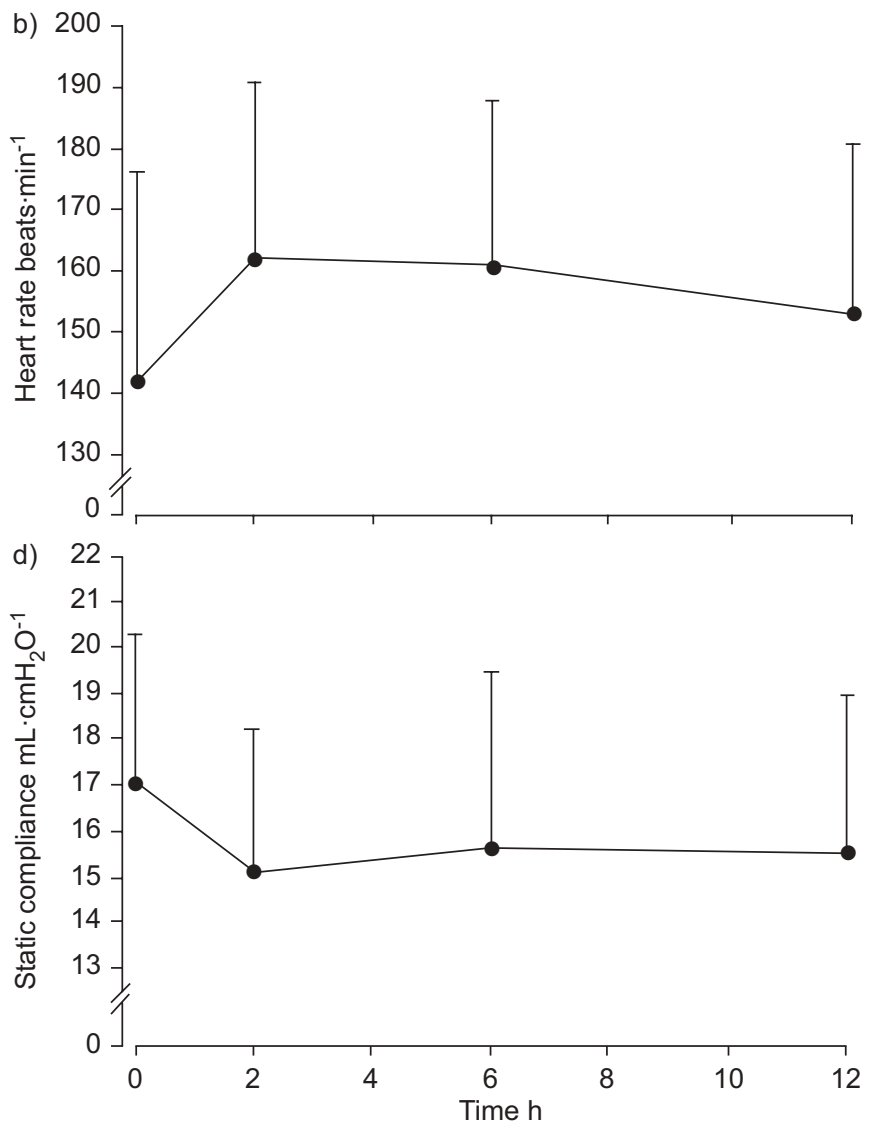

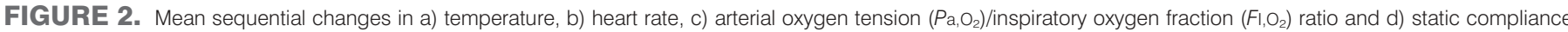
during the first $12 \mathrm{~h}$ after Pseudomonas aeruginosa inoculation in all piglets studied $(\mathrm{n}=15)$. Data are expressed as mean $\pm \mathrm{sD}$. $\mathrm{p}$-values are from Friedman paired test. a) and c) $p<0.001$; b) $p=0.001$; d) $p=0.09$ 
(extension along different secondary lobes); and 5: abscessed pneumonia (cellular necrosis coexisting with disruption of cellular architecture). Pneumonia was limited to the last three categories. Classification of each specimen was based upon the worst category observed.

\section{Statistical analysis}

All data are expressed as mean $\pm S D$ or mean $\pm S E M$, as appropriate. Qualitative or categorical variables were compared using the Chi-squared test. Quantitative variables between the three groups were compared using the one-way ANOVA test. Quantitative variables over the time were compared using the Friedman nonparametric test. A p-value $<0.05$ was considered statistically significant (all two-tailed).

\section{Approval by the institutional committee}

All animals were treated in compliance with the guidelines of the Ethics Committee and Direction of Investigation of the Hospital de Clínicas "José de San Martín", University Buenos Aires (Buenos Aires, Argentina) and the Guide for the Care and use of Laboratory Animals [34].

\section{RESULTS}

A total of 15 animals were studied after excluding the four that died during the first $12 \mathrm{~h}$ before randomisation.

\section{Clinical haemodynamic changes and respiratory mechanics after inoculation of P. aeruginosa (before randomisation)}

As a result of the inoculation of $P$. aeruginosa, a series of clinical, haemodynamic, pulmonary mechanics and gas exchange alterations were observed in the animals studied $(n=15)$. As shown in figure 2, early increases in body temperature and in heart rate were observed, being significant at $12 \mathrm{~h}$. Arterial oxygen tension $\left(\mathrm{Pa}_{\mathrm{a}} \mathrm{O}_{2}\right) / \mathrm{FI}, \mathrm{O}_{2}$ values decreased significantly after $12 \mathrm{~h}$, reflecting a marked impairment in pulmonary gas exchange. The static compliance values also decreased after inoculation, although the differences did not reach statistical significance. No changes were observed in mean arterial pressure.

\section{Outcome with specific treatments}

As stated above, $12 \mathrm{~h}$ after the inoculation of $P$. aeruginosa, the animals were randomised into three groups. When the groups were compared, no significant changes were observed in the sequential physiological measurements that were performed. However, regarding the laboratory parameters, an increase in serum glucose levels $(96 \mathrm{~h}$ ) and white blood cell count (84 and $96 \mathrm{~h}$ ) were detected in the CIP+GC group (table 1). No differences in the rest of the laboratory results were found (data not shown).

\section{Respiratory mechanics and gas exchange}

Contrary to what occurred in the control and CIP groups, the animals in the CIP+GC group showed a progressive improvement in static compliance (fig. 3). Gas exchange, reflected by the $\mathrm{Pa}, \mathrm{O}_{2} / \mathrm{FI}_{1} \mathrm{O}_{2}$ ratio was impaired in both the control group and the CIP group. In contrast, animals from the CIP+GC group demonstrated a discrete improvement in the $\mathrm{Pa}_{1} \mathrm{O}_{2} / \mathrm{FI}, \mathrm{O}_{2}$ ratio although the differences with the other two groups did not reach statistical significance (fig. 3). $\mathrm{pH}$, bicarbonate and lactate values remained within the normal range in all groups (data not shown).

\section{TABLE 1 Sequential measurements of physiological and laboratory parameters during the study in the three groups of piglets}

\begin{tabular}{|c|c|c|c|c|c|}
\hline & $12 \mathrm{~h}$ & $24 \mathrm{~h}$ & $48 \mathrm{~h}$ & $72 \mathrm{~h}$ & $96 \mathrm{~h}$ \\
\hline \multicolumn{6}{|c|}{ Heart rate beats $\cdot \min ^{-1}$} \\
\hline Control & $173 \pm 36$ & $142 \pm 28$ & $130 \pm 18$ & $136 \pm 16$ & $137 \pm 22$ \\
\hline CIP & $144 \pm 53$ & $136 \pm 31$ & $129 \pm 45$ & $132 \pm 17$ & $121 \pm 14$ \\
\hline $\mathrm{CIP}+\mathrm{GC}$ & $141 \pm 18$ & $130 \pm 10$ & $116 \pm 11$ & $121 \pm 06$ & $131 \pm 19$ \\
\hline \multicolumn{6}{|c|}{ Arterial pressure $\mathrm{mmHg}$} \\
\hline Control & $105 \pm 22$ & $109 \pm 11$ & $116 \pm 22$ & $112 \pm 26$ & $110 \pm 24$ \\
\hline CIP & $118 \pm 12$ & $111 \pm 14$ & $114 \pm 17$ & $126 \pm 30$ & $120 \pm 26$ \\
\hline $\mathrm{CIP}+\mathrm{GC}$ & $127 \pm 16$ & $105 \pm 26$ & $113 \pm 21$ & $118 \pm 12$ & $122 \pm 14$ \\
\hline \multicolumn{6}{|c|}{ Temperature ${ }^{\circ} \mathbf{C}$} \\
\hline Control & $40.2 \pm 1.2$ & $40.0 \pm 0.6$ & $39.1 \pm 1.0$ & $39.1 \pm 0.7$ & $39.0 \pm 1.4$ \\
\hline CIP & $39.1 \pm 1.7$ & $38.6 \pm 1.2$ & $37.9 \pm 1.7$ & $37.9 \pm 1.5$ & $38.9 \pm 2.3$ \\
\hline $\mathrm{CIP}+\mathrm{GC}$ & $40.3 \pm 1.1$ & $39.5 \pm 1.2$ & $38.9 \pm 1.2$ & $38.7 \pm 1.4$ & $37.8 \pm 1.0$ \\
\hline \multicolumn{6}{|c|}{ Glucose $\mathrm{mg} \cdot \mathrm{dL}^{-1}$} \\
\hline Control & $115 \pm 21$ & $93 \pm 27$ & $97 \pm 34$ & $70 \pm 34$ & $64 \pm 28^{*}$ \\
\hline CIP & $120 \pm 55$ & $122 \pm 80$ & $109 \pm 40$ & $124 \pm 52$ & $88 \pm 32^{\star}$ \\
\hline $\mathrm{CIP}+\mathrm{GC}$ & $112 \pm 41$ & $104 \pm 22$ & $118 \pm 18$ & $140 \pm 31$ & $171 \pm 52^{*}$ \\
\hline \multicolumn{6}{|c|}{ WBC $\times 10^{9}$ cells $\cdot L^{-1}$} \\
\hline Control & $16200 \pm 8760$ & $18720 \pm 11450$ & $15230 \pm 4456$ & $11610 \pm 6120^{*}$ & $13010 \pm 3850^{*}$ \\
\hline CIP & $17200 \pm 10241$ & $18920 \pm 7391$ & $21440 \pm 12697$ & $24400 \pm 9693^{*}$ & $20850 \pm 9903^{*}$ \\
\hline $\mathrm{CIP}+\mathrm{GC}$ & $15600 \pm 2899$ & $27820 \pm 8699$ & $26800 \pm 5338$ & $28125 \pm 5208^{*}$ & $26900 \pm 2787^{*}$ \\
\hline
\end{tabular}

Data are expressed as mean \pm SD. CIP: ciprofloxacin group; CIP+GC: ciprofloxacin plus glucocorticoids group; WBC: white blood cell count. *: $p<0.05$ between the three groups (ANOVA test) 

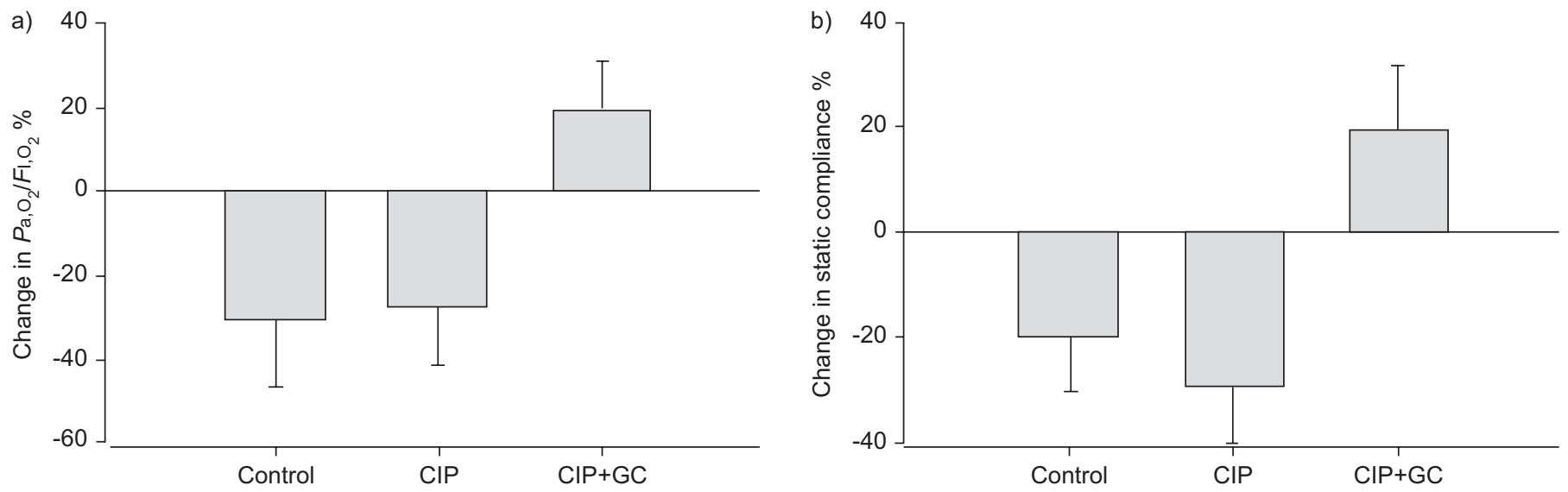

FIGURE 3. a) Arterial oxygen tension $\left(\mathrm{Pa}_{\mathrm{a}} \mathrm{O}_{2}\right)$ /inspiratory oxygen tension $\left(\mathrm{Fl}, \mathrm{O}_{2}\right)$ ratio and $\left.\mathrm{b}\right)$ static compliance measurements in the three groups of piglets studied. Results are expressed as percentage of change between 12 and $96 \mathrm{~h}$ after Pseudomonas aeruginosa inoculation. p-values are obtained using ANOVA test. CIP: ciprofloxacin group; CIP+GC: ciprofloxacin plus glucocorticoids group. a) $p=0.32$; b) $p=0.01$.

\section{Pulmonary and systemic inflammatory response}

At baseline, no differences were observed among the groups in the concentration of any of the different cytokines in BAL fluid (fig. 4). At the end of the study, an increase was observed in the levels of the different cytokines evaluated, with the highest concentration always seen in the control group, and the levels of these cytokines in the CIP group were always lower than in the controls. Interestingly, in the CIP+GC group cytokine levels showed the lowest values, with statistically significant differences in IL-6 concentrations (fig. 4). Concentrations of CRP in
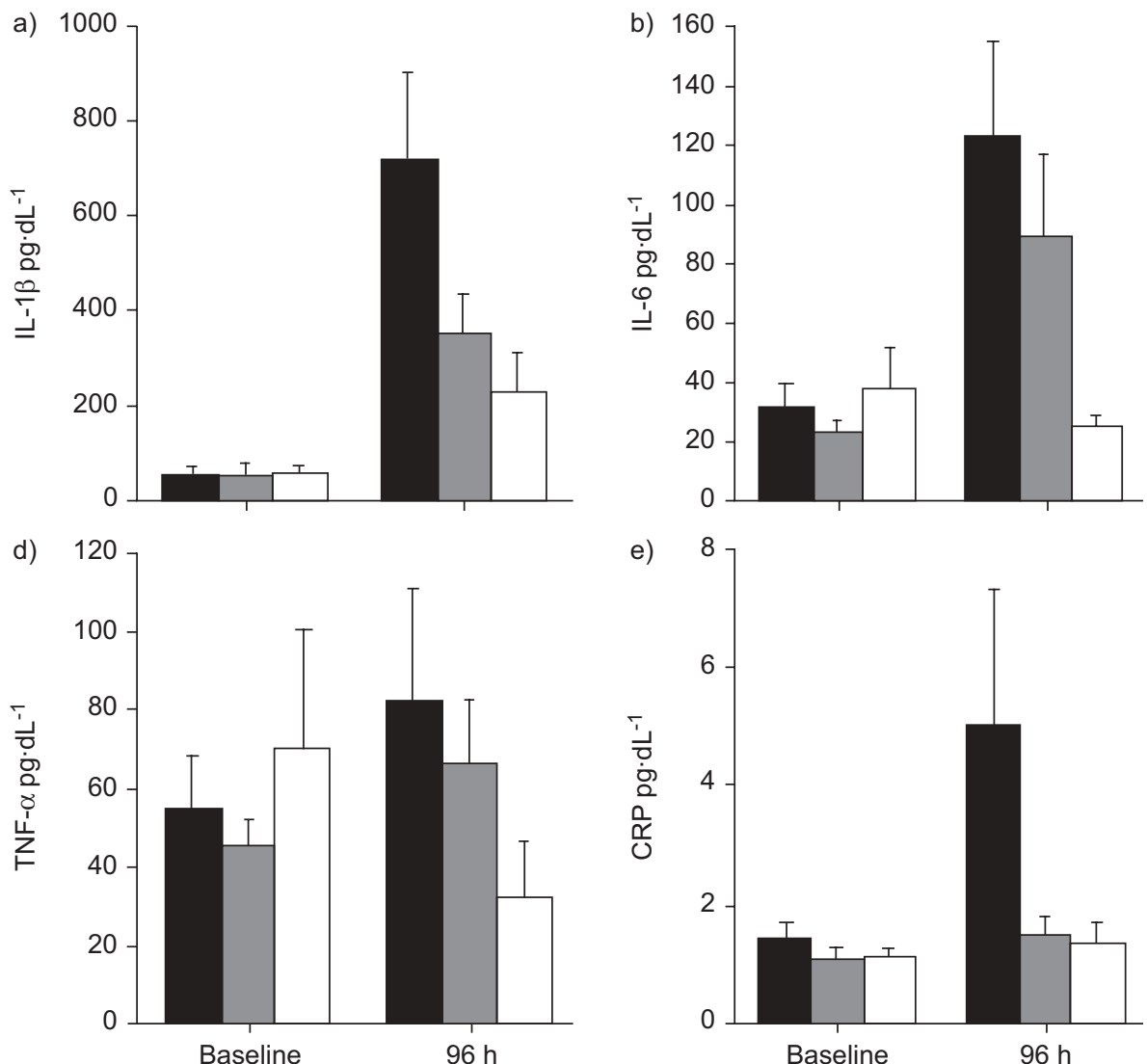

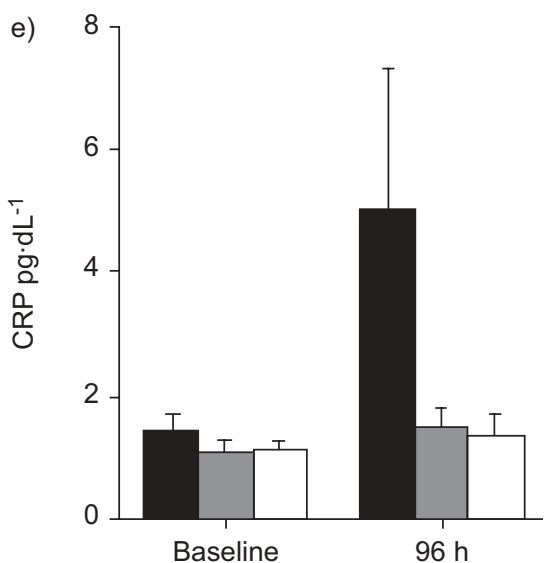

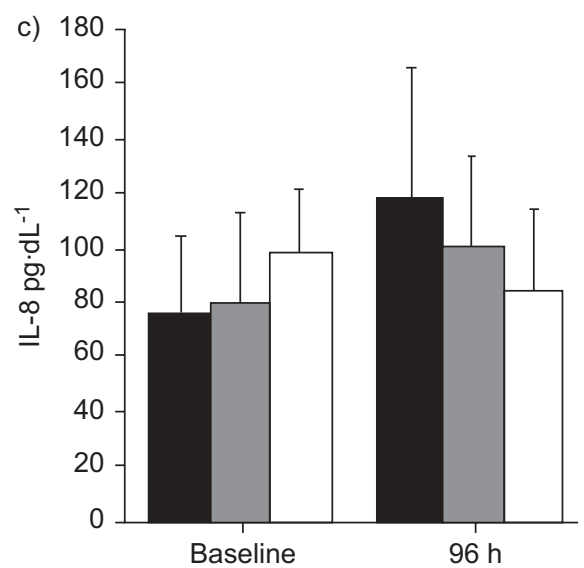

FIGURE 4. Values of bronchoalveolar lavage concentrations of a) interleukin (IL)-1 $\beta$, b) IL-6, C) IL-8, d) tumour necrosis factor (TNF)- $\alpha$ and e) C-reactive protein (CRP) at baseline and at the end of the study $(96 \mathrm{~h})$ in the three groups of piglets ( $\mathbf{\square}$ : control; $\mathbf{\square}$ : ciprofloxacin; $\square$ : ciprofloxacin plus glucocorticoids). Data are expressed as mean \pm SEM. At baseline, values are always homogeneus in the three groups $(p>0.1)$. After $96 h, p$-values from ANOVA test are as follows. a) $p=0.40 ; b) p=0.03 ; c) p=0.19$; d) $p=0.30$; and e) $p=0.41$. 


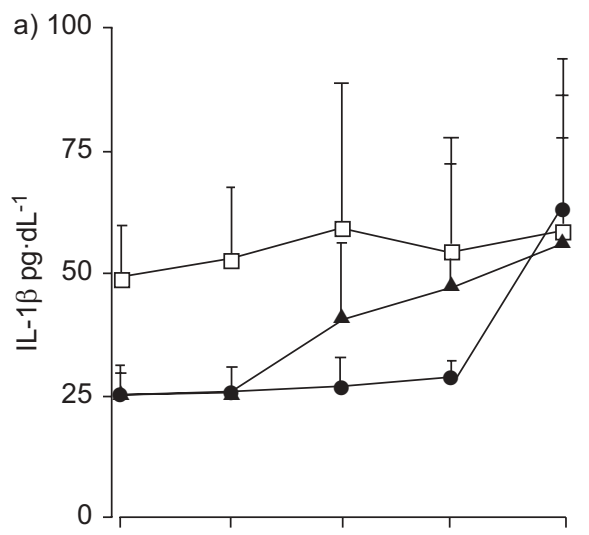

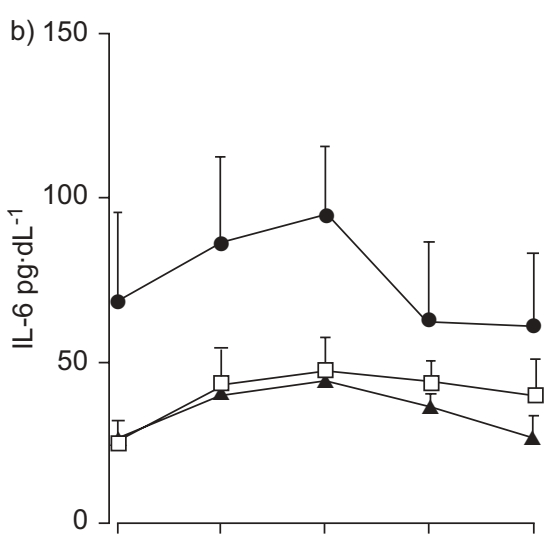

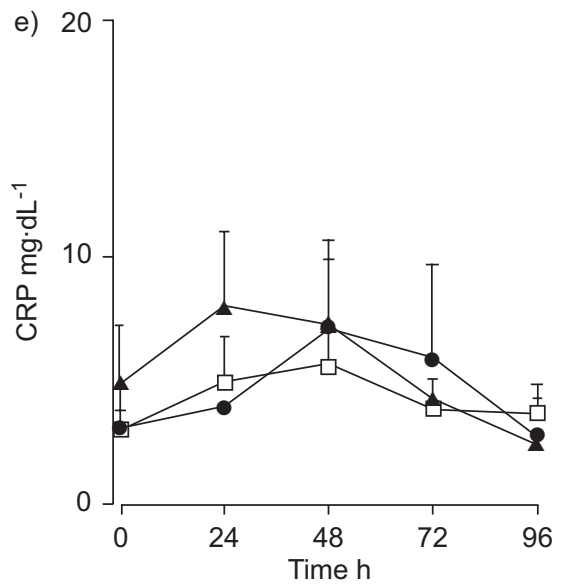

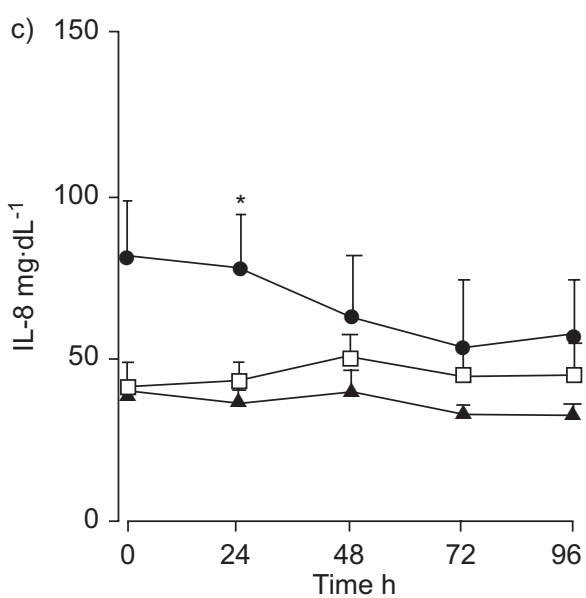

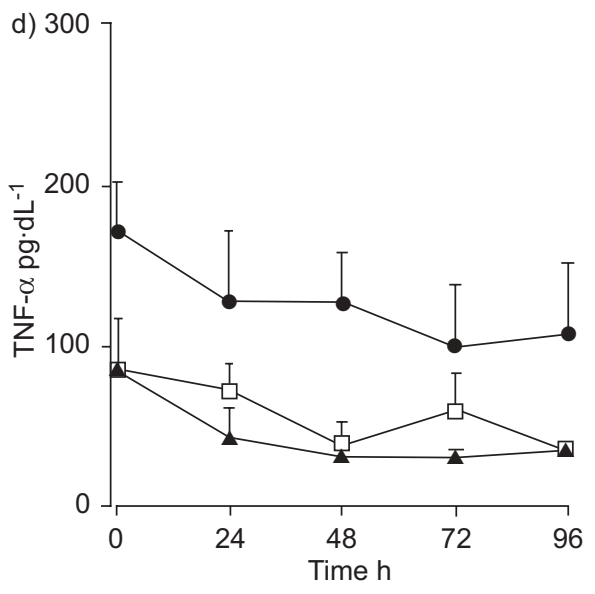

FIGURE 5. Sequential determinations of a) interleukin (IL)-1 $\beta$, b) IL-6, c) IL-8, d) tumour necrosis factor (TNF)- $\alpha$ and e) C-reactive protein (CRP) in serum throughout the study are shown for the ciprofloxacin group $(\bullet)$; ciprofloxacin plus glucocorticoid group $(\mathbf{\Lambda})$ and controls $(\square)$. Data are expressed as mean \pm SEM. The ANOVA test was used to compare the differences between the three groups every $24 \mathrm{~h} .{ }^{*}$ : $\mathrm{p}<0.05$.

BAL fluid followed the same pattern with low and homogeneous values at baseline and a marked increase at $96 \mathrm{~h}$ in the control group, a moderate rise in the CIP group and the lowest increase in the CIP+GC group (fig. 4).

Contrary to what was observed in BAL fluid, no consistent pattern was observed on the dynamics of the cytokines evaluated in serum (fig. 5). Difference between groups were observed in serum IL-8 after $24 \mathrm{~h}(\mathrm{p}=0.04)$.

\section{Microbiology}

Microbiological findings are shown in table 2. In the control group, BAL and lung cultures demonstrated P. aeruginosa in all the samples evaluated. In contrast, in the treated groups (CIP and $\mathrm{CIP}+\mathrm{GC}), P$. aeruginosa was isolated in BAL fluid from only two out of the five animals. Cultures of lung tissue demonstrated the presence of $P$. aeruginosa in all but one piglet from each group. The global bacterial burden showed significantly lower bacterial counts in both BAL and lung cultures in the $\mathrm{CIP}+\mathrm{GC}$ group $(\mathrm{p}=0.03$ and $\mathrm{p}=0.01$, respectively; fig. 6).

Blood cultures were negative in all piglets except in one control animal, which had positive cultures for $P$. aeruginosa.

\section{Histopathological findings}

According to the established criteria, $100 \%$ of animals in the control group, $80 \%$ (four out of five) in the CIP group and $40 \%$ (two out of five) in the CIP+GC group showed evidence of pneumonia at the end of the study. Of the 30 lung samples examined, pneumonia was present in $80 \%$ (eight out of 10) of the samples of the control group, in $60 \%$ (six out of 10) of the CIP group and in $30 \%$ (three out of 10 ) of the samples in the CIP+GC group $(\mathrm{p}=0.09)$.

Different grades of pneumonia severity were observed (table 3). Severe pneumonia was present in $60 \%$ of the pulmonary biopsies in the control group, $60 \%$ in the CIP group and $30 \%$ in the CIP+GC group $(p=0.08)$.

No differences in other lesions, including pleural involvement, vascular abnormalities and alveolar damage, were found among the three groups of animals studied.

\section{DISCUSSION}

The results of the present study in an animal model of pneumonia due to $P$. aeruginosa suggest that the addition of systemic GC to targeted antibiotic therapy diminishes the lung-associated inflammatory response and the bacterial lung burden. 
TABLE 2 Bacteriological results performed at the end of the study

\begin{tabular}{|c|c|c|c|c|c|}
\hline \multirow[t]{2}{*}{ Group } & \multicolumn{2}{|c|}{ BAL culture cfu $\cdot \mathrm{mL}^{-1}$} & \multicolumn{2}{|c|}{ Lung culture $\mathrm{cfu} \cdot \mathrm{gr}^{-1}$} & \multirow[t]{2}{*}{ Blood } \\
\hline & More involved lobe & More preserved lobe & More involved lobe & More preserved lobe & \\
\hline Control & P. aeruginosa $\left(10^{4}\right)$ & P. aeruginosa $\left(10^{4}\right)$ & P. aeruginosa $\left(10^{4}\right)$ & P. aeruginosa $\left(10^{4}\right)$ & Negative \\
\hline Control & P. aeruginosa $\left(10^{4}\right)$ & P. aeruginosa $\left(10^{4}\right)$ & P. aeruginosa $\left(10^{4}\right)$ & P. aeruginosa $\left(10^{4}\right)$ & Negative \\
\hline Control & P. aeruginosa $\left(10^{4}\right)$ & P. aeruginosa $\left(10^{4}\right)$ & P. aeruginosa $\left(10^{4}\right)$ & P. aeruginosa $\left(10^{4}\right)$ & Negative \\
\hline \multirow[t]{2}{*}{ Control } & P. aeruginosa $\left(10^{5}\right)$ & P. aeruginosa $\left(10^{4}\right)$ & P. aeruginosa $\left(10^{4}\right)$ & P. aeruginosa $\left(10^{4}\right)$ & Negative \\
\hline & & CN Staphylococcus $\left(10^{2}\right)$ & & & \\
\hline CIP & Negative & CN Staphylococcus $\left(10^{3}\right)$ & P. aeruginosa $\left(10^{2}\right)$ & CN Staphylococcus $\left(10^{3}\right)$ & Negative \\
\hline CIP & P. aeruginosa $\left(10^{3}\right)$ & P. aeruginosa $\left(10^{2}\right)$ & Negative & Negative & Negative \\
\hline CIP & P. aeruginosa $\left(10^{4}\right)$ & P. aeruginosa $\left(10^{2}\right)$ & P. aeruginosa $\left(10^{4}\right)$ & P. aeruginosa $\left(10^{4}\right)$ & Negative \\
\hline CIP & Negative & Negative & $P$. aeruginosa $\left(10^{2}\right)$ & Negative & Negative \\
\hline $\mathrm{CIP}+\mathrm{GC}$ & Negative & Negative & P. aeruginosa $\left(10^{2}\right)$ & Negative & Negative \\
\hline $\mathrm{CIP}+\mathrm{GC}$ & P. aeruginosa $\left(10^{2}\right)$ & Negative & Negative & Negative & Negative \\
\hline $\mathrm{CIP}+\mathrm{GC}$ & Negative & Negative & P. aeruginosa $\left(10^{3}\right)$ & P. aeruginosa $\left(10^{3}\right)$ & Negative \\
\hline
\end{tabular}

BAL: bronchoalveolar lavage; cfu: colony forming unit. P. aeruginosa: Pseudomonas aeruginosa; CIP: ciprofloxacin group; CIP+GC: ciprofloxacin plus glucocorticoid group; $\mathrm{CN}$ : coagulase-negative. All blood culture results were obtained as two consistent results from two tests.

Recent clinical evidence shows that low doses of hydrocortisone decrease mortality in severe CAP [19, 35]. GCs might exert their beneficial effect by counteracting the excessive release of inflammatory mediators that occurs in severe pulmonary infections. In the present study, in piglets treated with ciprofloxacin and GC, the concentration of IL-6 in the lung is attenuated. This attenuation is more pronounced than the one observed in animals receiving only targeted antibiotic. Levels of inflammatory mediators in BAL in the CIP+GC group were comparable to those observed at baseline, before the inoculation of bacteria, suggesting an efficient anti-inflammatory role of GC, particularly in reference to IL-6. In the present model signs of severe sepsis were not observed, probably justifying the absence of an important systemic inflammatory response.

Animals treated with ciprofloxacin and GC not only had an attenuated local inflammatory response; remarkably, they also had lower BAL and lung bacterial counts than the other two groups of animals, suggesting a more efficient bacterial eradication capacity when both compounds were associated. In fact, decrements of $0.5 \log \mathrm{cfu} \cdot \mathrm{mL}^{-1}$ and $0.8 \log \mathrm{cfu} \cdot \mathrm{g}^{-1}$ were observed in the mean BAL and lung tissue bacterial burden when comparing animals in the CIP+GC group to animals
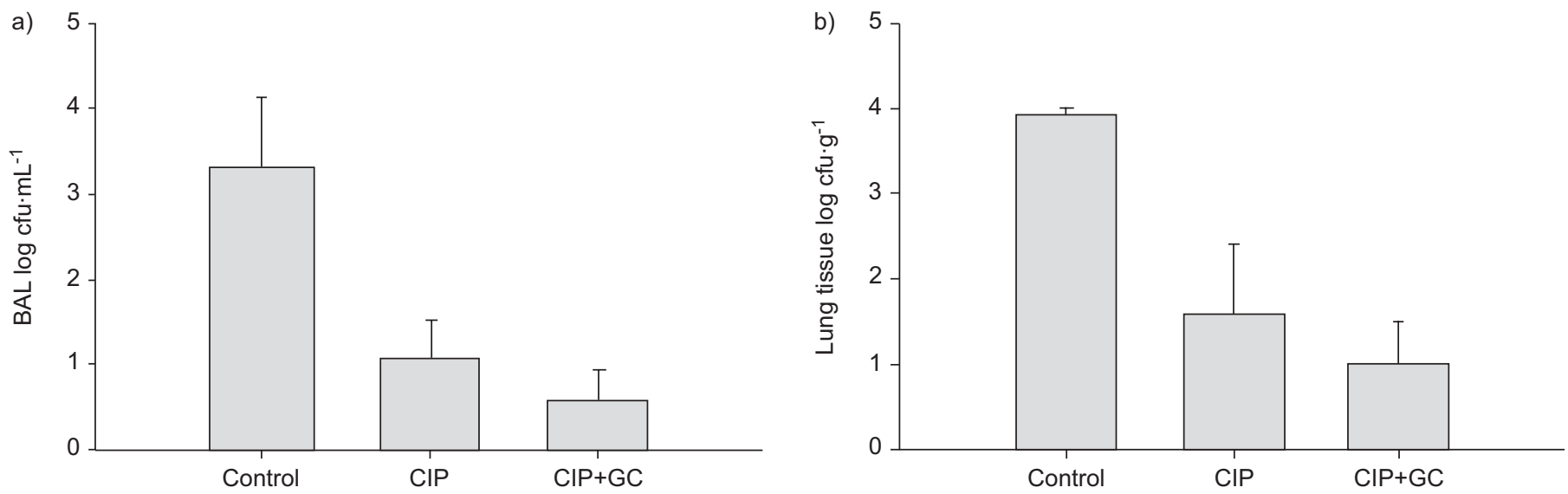

FIGURE 6. Global bacterial burden in the three groups of animals evaluated both in a) bronchoalveolar lavage (BAL; expressed as log colony forming units (cfu). $\mathrm{mL}^{-1}$ ) and $b$ ) in lung tissue (expressed as $\log c f u \cdot g^{-1}$ ). CIP: ciprofloxacin; GC: glucocorticoid. $p$-values were obtained using ANOVA test. a) $\left.p=0.03 ; b\right) p=0.01$. 


\begin{tabular}{lcc} 
TABLE 3 & Histopathological findings \\
\cline { 2 - 3 } Group & \multicolumn{2}{c}{ Pneumonia score } \\
\cline { 2 - 3 } & More involved lobe & More preserved lobe \\
\hline Control & Pneumonia & Bronchiolitis \\
Control & Confluent pneumonia & Confluent pneumonia \\
Control & Abscessed pneumonia & Confluent pneumonia \\
Control & Pneumonia & Purulent mucous plugging \\
Control & Abscessed pneumonia & Confluent pneumonia \\
CIP & Confluent pneumonia & Nonspecific abnormalities \\
CIP & Purulent mucous plugging & Nonspecific abnormalities \\
CIP & Confluent pneumonia & Bronchiolitis \\
CIP & Confluent pneumonia & Confluent pneumonia \\
CIP & Abscessed pneumonia & Confluent pneumonia \\
CIP+GC & Purulent mucous plugging & Bronchiolitis \\
CIP+GC & Purulent mucous plugging & Purulent mucous plugging \\
CIP+GC & Purulent mucous plugging & Nonspecific abnormalities \\
CIP+GC & Confluent pneumonia & Confluent pneumonia \\
CIP+GC & Confluent pneumonia & Purulent mucous plugging \\
\hline
\end{tabular}

CIP: ciprofloxacin group; $\mathrm{CIP}+\mathrm{GC}$ : ciprofloxacin plus glucocorticoid group.

treated only with ciprofloxacin. Although the small number of animals in these two groups precludes statistical comparisons, it is possible that this decrement may be remarkable from a clinical viewpoint. In fact, human studies with other types of respiratory infections have shown a parallel decrease in both bacterial burden and lung inflammatory response [36].

The beneficial effect of the simultaneous administration of ciprofloxacin and GC is also suggested by the present findings in the histopathological analysis of lung samples. Animals treated with ciprofloxacin and GC showed pneumonia in only $30 \%$ of the lobes evaluated compared with $60 \%$ in animals treated with ciprofloxacin. Also, pneumonia, defined as abscessed or confluent pneumonia, was present in $60 \%$ of the pulmonary biopsies in the CIP+GC group of animals, compared with $30 \%$ in animals treated with ciprofloxacin. Again, and although differences were not statistically significant, probably due to the small number of animals studied, these results could have clinical significance.

MeduRI et al. [37] in an in vitro study, have demonstrated that certain bacterial strains, such as $P$. aeruginosa, have receptors for the cytokines IL-1 $1 \beta$ and TNF- $\alpha$ and the exposure of bacteria to these cytokines enhance their growth and virulence. GCs might restore the impaired capacity of phagocytic cells produced by an excessive inflammation. Exposing human monocytic (U937) cells to progressively higher concentrations of lipopolysaccarides (LPSs) enhanced the intracellular survival and replication of different species of bacteria, including P. aeruginosa [37]. More importantly, when exposed to graded concentrations of methylprednisolone, U937 cells previously stimulated with LPS were able to suppress bacterial replication efficiently in a concentration-dependent manner. Finally, mRNA levels of TNF- $\alpha$, IL-1 $\beta$ and IL- 6 in LPS-activated cells were reduced by treatment of such cells with methylprednisolone [37].
These studies reinforce the present findings in the animal model of severe pneumonia and suggest that the impaired ability of phagocytic cells to eradicate bacteria by an excessive inflammatory response may be counterbalanced by the administration of GC.

Some methodological considerations must be taken into account for the proper evaluation of the results. Animal models cannot reflect all the physiopathological aspects of severe pneumonia pathogenesis, a dynamic process that involves a wide spectrum of pathogens and complex interactions with host defences favouring bacterial growth [38]. Moreover, the exogenous administration of highly bacterial inoculums in a previously healthy animal does not necessarily reflect the complexities of the development of pneumonia.

Also, the potentially harmful side-effects due to GC treatment and the rebound effect that their tapering can cause in the evolution of the inflammatory process are matters of an intense debate [14, 16, 39-41]. In this sense, failed or delayed recognition of infections in the presence of a blunted febrile response represents a serious threat. Also, other adverse events, such as hyperglycaemia and neuromyopathy, must be also taken into consideration when using GCs as an adjuvant therapy. Strict infection surveillance programmes and determination of the optimal dose of GC to be used can help in this respect. In the present study, an increase in the white blood cell count and higher levels of glycaemia was observed in animals receiving GCs. However, no other remarkable side-effects were observed at the steroid doses used.

Finally, the current authors recognise that mechanical ventilation may indeed alter the inflammatory response. It is known that mechanical ventilation with high VTs aggravates lung injury in patients with acute lung injury or ARDS. The effect of ventilation in patients without pre-existing lung injury is not so well characterised [42]. Certainly, in the present study it cannot be ruled out that mechanical ventilation had some influence on the observed inflammatory response. However, the potential influence of this factor may be partially offset by the fact that the three groups of animals compared were ventilated using the same settings.

In summary, in the present experimental model of pneumonia in ventilated piglets, the addition of glucocorticoids to targeted antibiotic treatment diminishes the local inflammatory response and decreases lung bacterial burden, and might improve the histopathological severity of pneumonia. These effects could potentially be beneficial from the clinical viewpoint. Further studies are necessary to elucidate not only which patients can potentially benefit from glucocorticoids, but also what optimal doses and duration of treatment are necessary to obtain an appropriate balance between the beneficial and harmful effects of inflammatory response.

\section{REFERENCES}

1 Bodí M, Rodríguez A, Solé-Violán J, et al. Antibiotic prescription for community-acquired pneumonia in the intensive care unit: impact of adherence to Infectious Diseases Society of America guidelines on survival. Clin Infect Dis 2005; 41: 1709-1716. 
2 Chastre J, Fagon JY. Ventilator-associated pneumonia. Am J Respir Crit Care Med 2002; 165: 867-903.

3 Fagon JY, Chastre J, Hance AJ, Montravers P, Novara A, Gibert C. Nosocomial pneumonia in ventilated patients: a cohort study evaluating attributable mortality and hospital stay. Am J Med 1993; 94: 281-288.

4 Heyland DK, Cook DJ, Griffith L, Keenan SP, BrunBuisson C. The attributable morbidity and mortality of ventilator-associated pneumonia in the critically ill patient. The Canadian Critical Trials Group. Am J Respir Crit Care Med 1999; 159: 1249-1256.

5 Leeper KV, Torres A. Community-acquired pneumonia in the intensive care unit. Clin Chest Med 1995; 16: 155-171.

6 Montón C, Torres A, El Ebiary M, Filella X, Xaubert A, de la Bellacasa JP. Cytokine expression in severe pneumonia: a bronchoalveolar lavage study. Crit Care Med 1999; 27: 1745-1753.

7 Fernández-Serrano S, Dorca J, Coromines M, Carratala J, Gudiol F, Manresa F. Molecular inflammatory responses measured in blood of patients with severe communityacquired pneumonia. Clin Diagn Lab Immunol 2003; 10: 813-820.

8 Ioanas M, Ferrer M, Cavalcanti M, et al. Causes and predictors of nonresponse to treatment of the intensive care unit-acquired pneumonia. Crit Care Med 2004; 32: 938-945.

9 Schutte H, Lohmeyer J, Rosseau S, et al. Bronchoalveolar and systemic cytokine profiles in patients with ARDS, severe pneumonia and cardiogenic pulmonary oedema. Eur Respir J 1996; 9: 1858-1867.

10 Meduri GU, Kohler G, Headley S, Tolley E, Stentz F, Postlethwaite A. Inflammatory cytokines in the BAL of patients with ARDS. Persistent elevation over time predicts poor outcome. Chest 1995; 108: 1303-1314.

11 Rhen T, Cidlowski JA. Antiinflammatory action of glucocorticoids-new mechanisms for old drugs. N Engl J Med 2005; 353: 1711-1723.

12 Monton C, Ewig S, Torres A, et al. Role of glucocorticoids on inflammatory response in nonimmunosuppressed patients with pneumonia: a pilot study. Eur Respir J 1999; 14: 218-220.

13 Keh D, Boehnke T, Weber-Cartens S, et al. Immunologic and hemodynamic effects of "low-dose" hydrocortisone in septic shock: a double-blind, randomized, placebo-controlled, crossover study. Am J Respir Crit Care Med 2003; 167: 512-520.

14 Sprung CL, Annane D, Keh D, et al. Hydrocortisone therapy for patients with septic shock. N Engl J Med 2008; 358: 111-124.

15 Meduri GU, Headley AS, Golden E, et al. Effect of prolonged methylprednisolone therapy in unresolving acute respiratory distress syndrome: a randomized controlled trial. JAMA 1998; 280: 159-165.

16 Steinberg KP, Hudson LD, Goodman RB, et al. Efficacy and safety of corticosteroids for persistent acute respiratory distress syndrome. N Engl J Med 2006; 354: 1671-1684.

17 Meduri GU, Marik P, Chorousos GP, et al. Steroid treatment in ARDS: a critical appraisal of the ARDS network trial and the recent literature. Intensive Care Med 2008; 34: 61-69.
18 Jantz MA, Sahn SA. Corticosteroids in acute respiratory failure. Am J Respir Crit Care Med 1999; 160: 1079-1100.

19 Confalonieri M, Urbino R, Potena A, et al. Hydrocortisone infusion for severe community-acquired pneumonia: a preliminary randomized study. Am J Respir Crit Care Med 2005; 171: 242-248.

20 Marquette $\mathrm{CH}$, Wermert D, Wallet F, Copin MC, Tonnel AB. Characterization of an animal model of ventilator-acquired pneumonia. Chest 1999; 115: 200-209.

21 Wermert D, Marquette $\mathrm{CH}$, Copin $\mathrm{MC}$, et al. Influence of pulmonary bacteriology and histology on the yield of diagnostic procedures in ventilator-acquired pneumonia. Am J Respir Crit Care Med 1998; 158: 139-147.

22 Goldstein I, Bughalo MT, Marquette $\mathrm{CH}$, et al. Mechanical ventilation-induced air-space enlargement during experimental pneumonia in piglets. Am J Respir Crit Care Med 2001; 163: 958-964.

23 Goldstein I, Wallet F, Nicolas-Robin A, Ferrari F, Marquette $\mathrm{CH}$, Rouby JJ. Lung deposition and efficiency of nebulized amikacin during Escherichia coli pneumonia in ventilated piglets. Am J Respir Crit Care Med 2002; 166: 1375-1381.

24 Elman M, Goldstein I, Marquette $\mathrm{CH}$, et al. Influence of lung aeration on pulmonary concentrations of nebulized and intravenous amikacin in ventilated piglets with severe bronchopneumonia. Anesthesiology 2002; 97: 199-206.

25 Ferrari F, Goldstein I, Nieszkowszka A, et al. Lack of lung tissue and systemic accumulation after consecutive daily aerosols of amikacin in ventilated piglets with healthy lungs. Anesthesiology 2003; 98: 1016-1019.

26 Tonnellier M, Ferrari F, Goldstein I, Sartorius A, Marquette $\mathrm{CH}$, Rouby JJ. Intravenous versus nebulized ceftazidime in ventilated piglets with and without experimental bronchopneumonia: comparative effects of helium and nitrogen. Anesthesiology 2005; 102: 995-1000.

27 Luna CM, Baquero S, Gando S, et al. Experimental severe Pseudomonas aeruginosa pneumonia and antibiotic therapy in piglets receiving mechanical ventilation. Chest 2007; 132 523-531.

28 Sibila O, Agustí C, Torres A, et al. Experimental Pseudomonas aeruginosa pneumonia: evaluation of the associated inflammatory response. Eur Respir J 2007; 30: 1167-1172.

29 Arancibia F, Bauer TT, Ewig S, et al. Community-acquired pneumonia due to Gram-negative bacteria and Pseudomonas aeruginosa: incidence, risk, and prognosis. Arch Intern Med 2002; 162: 1849-1858.

30 Rossi A, Polese G, Brandi G, Conti G. Intrinsic positive end-expiratory pressure (PEEPi). Intensive Care Med 1995; 2: 522-536.

31 él-Ebiary M, Torres A, González J, et al. Quantitative cultures of endotracheal aspirates for the diagnosis of ventilator-associated pneumonia. Am Rev Respir Dis 1993; 147: 1552-1557.

32 Balows A, Hausler WJJ. Manual of Clinical Microbiology. 5th Edn. Washington, American Society for Microbiology, 1991.

33 Marquette $\mathrm{CH}$, Copin $\mathrm{MC}$, Wallet $\mathrm{F}$, et al. Diagnostic tests for pneumonia in ventilated patients: prospective 
evaluation of diagnostic accuracy using histology as a diagnostic gold standard. Am J Respir Crit Care Med 1995; 151: 1878-1888.

34 National Research Council. Guide for the Care and use of Laboratory Animals. Washington, National Academy Press, 1985.

35 Agustí C, Rañó A, Filella X, et al. Pulmonary infiltrates in patients receiving long-term glucocorticoid treatment: etiology, prognostic factors, and associated inflammatory response. Chest 2003; 123: 488-498.

36 Angrill J, Agustí C, De Celis R, et al. Bronchial inflammation and colonization in patients with clinically stable bronchiectasis. Am J Respir Crit Care Med 2001; 164: 1628-1632.

37 Meduri GU, Kanangat S, Bronze M, et al. Effects of methylprednisolone on intracellular bacterial growth. Clin Diagn Lab Immunol 2001; 8: 1156-1163.
38 Craven DE, Duncan RA. Preventing ventilator-associated pneumonia: tiptoeing through a minefield. Am J Respir Crit Care Med 2006; 173: 1297-1298.

39 Lefering R, Neugebauer EM. Steroid controversy in sepsis and septic shock: a meta-analysis. Crit Care Med 1995; 23: 1294-1303.

40 Herrige MS, Cheung AM, Tansey CM, et al. One-year outcomes in survivors of the acute respiratory distress syndrome. N Eng J Med 2003; 348: 683-693.

41 De Jonghe B, Sharshar T, Lefaucheur JP, et al. Paresis acquired on the intensive care unit: a prospective multicenter study. JAMA 2002; 288: 2859-2867.

42 Wolthius EK, Choi G, Dessing MC, et al. Mechanical ventilation with lower tidal volumes and positive endexpiratory pressure prevents pulmonary inflammation in patients without preexisting lung injury. Anesthesiology 2008; 108: 46-54. 